\title{
Novel Fiberglass Resistance Pole Training Implement: Reference Values for Exercise Prescription
}

\author{
Steve C Glass* and Lindsey Remski \\ Human Performance Laboratory, Department of Movement Science, USA
}

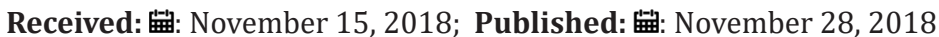

*Corresponding author: Steve C Glass, Human Performance Laboratory, Department of Movement Science, USA

\section{Abstract}

Background: Functional strength training often employs the use of elastic materials that allow for versatile movement. New materials have been developed to provide more options for functional resistance training. Core Stix ${ }^{\mathrm{TM}}$ is a new technology that utilizes fiberglass polymer resistance poles flexed through a range of motion, creating tension. This study quantified the tension of Core Stix ${ }^{\mathrm{TM}}$ poles across different pole colors and degrees of flexion. Furthermore, the influence of hand position on tension within each pole was assessed.

Methods: A basic Core Stix Fitness System was utilized for research and consisted of a platform with socket inserts and 5 different resistance pole intensities. Each pole intensity was assessed for tension at 10 degree increments, from $0-60$ o as per the suggested manufacturing limits of use. Additionally, the large foam resistance handle was divided into 4 equal segments (hand positions), and force measures were taken at each position across poles and degrees of flexion. Tension was measured 4 times, and the mean used for analysis. Repeated measures ANOVAs with Tukey post hoc comparisons assessed differences across pole types and hand position.

Results: A linear relationship between pole flexion and resistance was observed. A significant difference in loading was shown between each of the pole colors, while hand placement became a significant factor between the top and bottom position.

Conclusion: Resistance loading across poles and degrees of flexion is linear and graduated. Resistance can be varied by changing hand position or poles. Practitioners can use these values for more precise exercise programming.

Keywords: Elastic Resistance; Functional Training; Fiberglass Pole; Exercise Prescription; Strength Training; Strength Rehabilitation

\section{Introduction}

Training to improve functional strength requires performing exercises that overload the muscle while also allowing for a variety of functional movements. The use of free weights or machines during exercise often prevents variations in angle, speed, and torso movements that are necessary for functional training. Alternative forms of resistive equipment have been developed using elastic bands or flexible materials, which overcome these limitations. Resistance bands are a popular option for muscular rehabilitation due to their ability to be used in a variety of movement planes and effectively strengthening the muscle. The bands are color-coded, with each color representing different resistance properties, creating a range of loading schemes. The amount of resistance elastic materials provide is dependent on the stretch deformation characteristics. Generally, the amount of tension provided increases proportionally with the amount of deformation the band undergoes. Studies have been published quantifying the resistance measurements of elastic bands. Hughes et al. [1] determined the resistance properties of 6 progressive levels of Thera-Band ${ }^{\mathrm{TM}}$ tubes during shoulder abduction exercise. The study showed a positive, linear relationship between tube length and tension, with significant tension differences between each of the different colored tubes. Uchida et al. [2] published data showing tension for TheraBand $^{\mathrm{TM}}$ elastic bands at strain values between $25 \%$ and $250 \%$ of resting length. By quantifying the resistance of these bands, these data provided useful information to practitioners that allows them to appropriately prescribe loads for training.

As technology has evolved, new materials have been developed to provide more options for functional resistance. Core $\mathrm{Stix}^{\mathrm{TM}}$ is a relatively new resistance training technology [3] currently available (http://www.corestix.com/). The training system consists of a platform with metal interfaces that contain sockets oriented in a variety direction (Figure 1). Fiberglass polymer resistance poles can be inserted into the sockets and flexed through a range of motion, creating tension as they are flexed. Materials made 
available by the company suggest a wide range of exercises can be performed for strength, functional training, and rehabilitation. To date, there are no data available regarding the resistive properties of Core $\mathrm{Stix}^{\mathrm{TM}}$ fiberglass poles. Five different pole intensities exist, differentiated by colors. Intensities range from purple (very light), white (light), yellow (moderate), blue (heavy), to red (very heavy). Like elastic bands, as the flex of the poles increase, resistance also increases. However, the amount of resistance provided by each of the poles throughout the suggested range of pole flexion $\left(0^{\circ}-60^{\circ}\right)$ is unknown. Additionally, the handhold area of the poles is large $(44 \mathrm{~cm})$, so variations in hand placement may influence the amount of tension within the same pole. The purpose of this study was to quantify the tension of Core Stix ${ }^{\mathrm{TM}}$ poles across the different pole colors at a variety of degrees of pole flexion. Furthermore, we wanted to examine the influence of hand position on tension within each pole. Our intent was to provide useful information for exercise prescription for various exercises using Core $\mathrm{Stix}^{\mathrm{TM}}$ resistive technology.

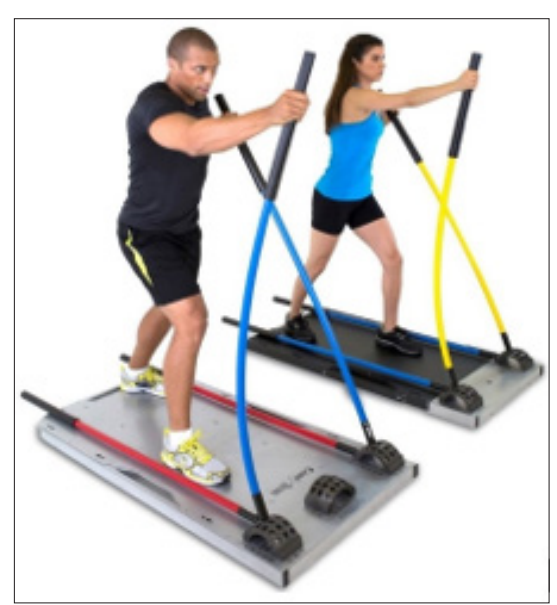

Figure 1: Example of Core Stix ${ }^{\mathrm{TM}}$ Training System.

\section{Materials and Methods}

A basic Core Stix Fitness System utilized for research and consisted of a platform with socket inserts and 5 different resistance pole intensities. Each pole intensity was assessed for tension at 10 degree increments, from $0-60^{\circ}$ as per the suggested manufacturing limits of use. Tension was measured 4 times, and the mean used for analysis. Since the tension changes as the pole flexes, we utilized a manual force measuring device that could be placed on the pole and would measure tension as the pole was flexed across its range.

\section{Pole Flex}

In order to assess pole flex and tension, each pole was placed in the central vertical socket of the metal baseplate. To assess tension, the pole was flexed in 10 degree increments, assessed using a digital inclinometer (Saunders Inclinometer, Fabrication Enterprises, White Plains, NY) attached to the center of the hand grip. Each pole was manually flexed by 1-2 researchers while assessing degrees of flex. When the inclinometer identified the precise point of flex, tension was recorded. Measurements were taken 4 times and the mean used for data analysis. In all cases the tension was recorded when the inclinometer measured the exact 10 degree increment.

\section{Pole Tension}

In order to assess tension as the poles flex, a manual muscle tester was used. The Nicholas Manual Muscle Tester (Lafayette Instruments. Lafayette, IN USA). The device was calibrated at zero and $22.6 \mathrm{~kg}$ for linear force measurement prior to each set of measures of each pole. Four cycles of pole tension measurements were completed, with calibration prior to each. Research has shown that the tester has an accuracy of $\pm 0.5 \mathrm{~kg}$ and a reliability of 0.96 to 0.98 for 3-6 repeated measure [4,5]. Intra-class correlation coefficients for tension across 4 measures was 99 .

\section{Handgrip Setting}

Since the manufacturer provided a $44 \mathrm{~cm}$ foam handle for using a range of handhold placements, we assessed tension differences across the handle by dividing it into $4,11 \mathrm{~cm}$ handgrip sections. Individual tension measurements were completed at each hand grip setting at 10 degree increments. Four measures at each setting were completed and the mean recorded. The pole handle demarcations, force tester and inclinometer set up is shown in Figure 2.

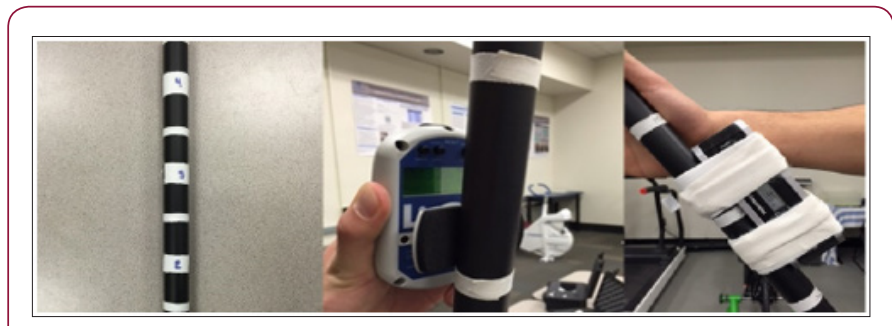

Figure 2: Pole handle demarcations, force tester, and inclinometer.

\section{Tension Assessment Technique}

The method of tension measurement was completed by placing the muscle tester on the individual hand grip setting, starting from the top setting (Labeled "One"). Holding the tester to the pole, the researcher flexed the pole while another researcher read the inclinometer reading. When the inclinometer read 10 degrees, the force measurement on the muscle tester was recorded. The pole was then flexed until 20 degrees, and force again measured. This continued up to 60 degrees of pole flex. Then handgrip setting "Two" though "Four" (bottom grip) was assessed across all poles and degrees of flex using the same method. The muscle tester was recalibrated after each hand grip setting cycle. All measures were assessed 4 times, and the mean of 4 measures was used for analysis.

\section{Analysis}

While the primary intent of this study was to provide descriptive data regarding pole tension at differing degrees of flex, repeated measures ANOVAs with Tukey post hoc comparisons were used to determine whether any statistically significant differences existed across pole types and hand position. Additionally, predictive equations for each pole were generated to estimate tension based on degree of flex using linear regression analysis. 


\section{Results and Observations}

\section{Descriptive Data}

Data from the mean of 4 trials of tension measurement at each degree of pole flex and each handhold setting are provided in Table 1(a-e). These data provide information for the practitioner regarding the amount of tension for exercise prescription purposes. Note that the lightest loading for each pole is provided by gripping the top portion of the foam handgrips, and the heaviest loading is the bottom grip. Table 2 describes the slope and intercept for the change in pole tension across degrees of flexion for each pole color. The regression equations provided provide the practitioner estimation equations for determining pole tension if degrees of flex are known. Correlation coefficients for each degree by tension relationship was 0.999 to 1.0 , indicating a positive linear change in pole tension across degree of pole flex.

Table 1: Pole tension by hand position and degree of pole flex. a) Purple Pole (“Very Light”).

\begin{tabular}{|c|c|c|c|c|c|}
\hline $\begin{array}{c}\text { Degrees of } \\
\text { Flex }\end{array}$ & $\begin{array}{c}\text { Bottom Grip } \\
\text { (1) }\end{array}$ & $\mathbf{2}$ & $\mathbf{3}$ & $\begin{array}{c}\text { Top Grip } \\
\mathbf{( 4 )}\end{array}$ & Mean $\mathbf{\text { SD }}$ \\
\hline 10 & 1.3 & 1.0 & 0.9 & 0.8 & $1.0 \pm 0.2$ \\
\hline 20 & 2.8 & 2.3 & 2.0 & 1.8 & $2.2 \pm 0.5$ \\
\hline 30 & 4.3 & 3.4 & 3.0 & 2.6 & $3.3 \pm 0.7$ \\
\hline 40 & 5.7 & 4.6 & 4.0 & 3.5 & $4.4 \pm 1.0$ \\
\hline 50 & 7.1 & 5.7 & 5.1 & 4.4 & $5.5 \pm 1.1$ \\
\hline 60 & 8.8 & 7.1 & 6.0 & 5.2 & $6.7 \pm 1.6$ \\
\hline
\end{tabular}

b) White Pole (“Light").

\begin{tabular}{|c|c|c|c|c|c|}
\hline $\begin{array}{c}\text { Degrees of } \\
\text { Flex }\end{array}$ & $\begin{array}{c}\text { Bottom Grip } \\
(\mathbf{1})\end{array}$ & $\mathbf{2}$ & $\mathbf{3}$ & $\begin{array}{c}\text { Top Grip } \\
\text { (4) }\end{array}$ & Mean \pm SD \\
\hline 10 & 2.6 & 2.1 & 1.8 & 1.5 & $2.0 \pm 0.5$ \\
\hline 20 & 5.5 & 4.4 & 3.8 & 3.1 & $4.2 \pm 1.0$ \\
\hline 30 & 8.2 & 6.7 & 5.6 & 4.7 & $6.3 \pm 1.5$ \\
\hline 40 & 11.0 & 9.0 & 7.6 & 6.3 & $8.5 \pm 2.0$ \\
\hline 50 & 13.9 & 11.3 & 9.7 & 8.0 & $10.7 \pm 2.5$ \\
\hline 60 & 16.8 & 13.7 & 11.0 & 9.8 & $12.8 \pm 3.1$ \\
\hline
\end{tabular}

c) Yellow Pole ("Moderate").

\begin{tabular}{|c|c|c|c|c|c|}
\hline $\begin{array}{c}\text { Degrees of } \\
\text { Flex }\end{array}$ & $\begin{array}{c}\text { Bottom Grip } \\
\text { (1) }\end{array}$ & $\mathbf{2}$ & $\mathbf{3}$ & $\begin{array}{c}\text { Top Grip } \\
\mathbf{( 4 )}\end{array}$ & Mean $\mathbf{\text { SD }}$ \\
\hline 10 & 4.9 & 3.9 & 3.4 & 2.8 & $3.7 \pm 0.9$ \\
\hline 20 & 10.2 & 8.2 & 6.8 & 5.8 & $7.7 \pm 1.9$ \\
\hline 30 & 15.3 & 12.5 & 10.6 & 8.8 & $11.8 \pm 2.8$ \\
\hline 40 & 20.5 & 16.8 & 14.3 & 11.8 & $15.8 \pm 3.7$ \\
\hline 50 & 25.6 & 21.2 & 18.2 & 15.0 & $20.2 \pm 4.5$ \\
\hline 60 & 30.4 & 25.1 & 21.7 & 18.4 & $23.9 \pm 5.1$ \\
\hline
\end{tabular}

Cite this article: Steve C Glass, Lindsey Remski. Novel Fiberglass Resistance Pole Training Implement: Reference Values for Exercise Prescription. Biomed J Sci \& Tech Res 11(3)-2018. BJSTR. MS.ID.002113. DOI: 10.26717/ BJSTR.2018.11.002113.

\begin{tabular}{|c|c|c|c|c|c|}
\hline $\begin{array}{c}\text { Degrees of } \\
\text { Flex }\end{array}$ & $\begin{array}{c}\text { Bottom Grip } \\
\text { (1) }\end{array}$ & $\mathbf{2}$ & $\mathbf{3}$ & $\begin{array}{c}\text { Top Grip } \\
\text { (4) }\end{array}$ & Mean \pm SD \\
\hline 10 & 6.8 & 5.1 & 4.6 & 3.7 & $5.0 \pm 1.3$ \\
\hline 20 & 13.6 & 10.7 & 9.0 & 7.9 & $10.3 \pm 2.5$ \\
\hline 30 & 20.7 & 16.2 & 13.8 & 11.9 & $15.6 \pm 3.8$ \\
\hline 40 & 27.2 & 21.5 & 18.5 & 15.6 & $20.7 \pm 5.0$ \\
\hline 50 & 33.3 & 27.7 & 23.8 & 20.0 & $26.2 \pm 5.7$ \\
\hline 60 & 38.7 & 32.9 & 27.4 & 24.1 & $30.8 \pm 6.4$ \\
\hline
\end{tabular}

e) Red Pole ("Very Heavy").

\begin{tabular}{|c|c|c|c|c|c|}
\hline $\begin{array}{c}\text { Degrees of } \\
\text { Flex }\end{array}$ & $\begin{array}{c}\text { Bottom Grip } \\
\text { (1) }\end{array}$ & $\mathbf{2}$ & $\mathbf{3}$ & $\begin{array}{c}\text { Top Grip } \\
\text { (4) }\end{array}$ & Mean \pm SD \\
\hline 10 & 8.1 & 6.9 & 5.3 & 4.7 & $6.2 \pm 1.5$ \\
\hline 20 & 16.6 & 14.0 & 11.3 & 9.7 & $12.9 \pm 3.0$ \\
\hline 30 & 25.5 & 21.2 & 17.6 & 14.9 & $19.8 \pm 4.6$ \\
\hline 40 & 33.0 & 26.9 & 23.2 & 19.6 & $25.7 \pm 5.7$ \\
\hline 50 & 41.2 & 33.8 & 29.5 & 25.3 & $32.4 \pm 6.8$ \\
\hline 60 & 48.3 & 40.2 & 34.6 & 30.5 & $38.4 \pm 7.7$ \\
\hline
\end{tabular}

Note: Tension reported in $\mathrm{kg}$.

Table 2: Regression equations to predict pole tension based on degree of pole reflex.

\begin{tabular}{|c|c|c|}
\hline Pole Type & Equation & $\begin{array}{c}\text { Correlation } \\
\text { Coefficient }\end{array}$ \\
\hline Purple (Very Light) & $\mathrm{y}=-0.116+0.114 \mathrm{x}$ & $\mathrm{r}=0.999$ \\
\hline White (Light) & $\mathrm{y}=-0.189+0.217 \mathrm{x}$ & $\mathrm{r}=1.0$ \\
\hline Yellow (Moderate) & $\mathrm{y}=-0.314+0.405 \mathrm{x}$ & $\mathrm{r}=1.0$ \\
\hline Blue (Heavy) & $\mathrm{y}=-0.045+0.518 \mathrm{x}$ & $\mathrm{r}=0.999$ \\
\hline Red (Very Heavy) & $\mathrm{y}=-0.038+0.644 \mathrm{x}$ & $\mathrm{r}=0.999$ \\
\hline
\end{tabular}

$y=$ Predicted pole tension. $x=$ Pole flex in degrees.

\section{Effect of Hand Position on Tension}

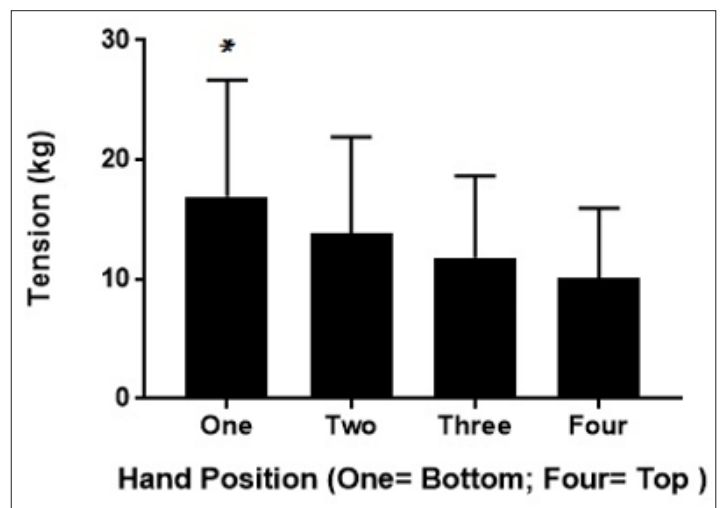

Figure 3: Comparison of mean pole tension across hand position.

Note: Handgrip setting One $>$ Four $\mathrm{p}<.05$

Figure 3 shows the comparison of mean pole tension (10-60 degrees combined) across hand position. ANOVA results showed a significant main effect, with post hoc Tukey test indicating the 
tension at the bottom grip ("One") was significantly greater than tension at the top grip ("Four"). For the general exerciser, who will most likely select a hand position somewhat in the center of the grip (grip "Two" and "Three"), there are no statistical differences in pole tension. 3.3 Pole Tension Across Degrees of Flex (Figure 4) shows the comparison across 10 to 60 degrees of pole flex for across all pole colors. ANOVA results showed significant main effects of pole color and post hoc Tukey tests indicated that all pole colors showed significant differences in tension between each other at all flex angles.

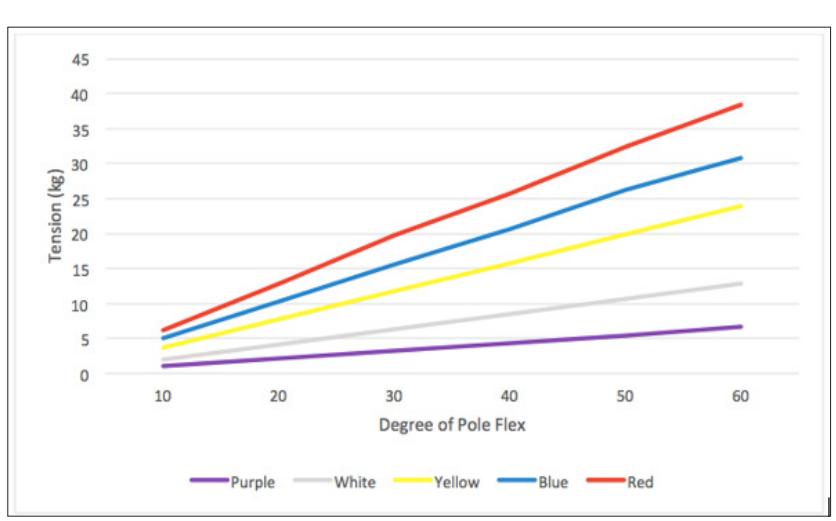

Figure 4: Comparison of tension across degrees of pole flexion for different pole colors.

\section{Discussion}

This is the first study to specifically examine the tension characteristics of a resistive pole training system. A linear relationship across increased pole flex and tension was observed, as well as significant differences in tension between the top and bottom hand grip positions. Significant differences in tension were seen between each of the pole colors, allowing for exercise progression by changing poles to the next resistive level. Loading schemes can also be adjusted within each pole by either extending the range of motion during an exercise to increase pole flexion, or by lowering the hand grip position. Exercise prescription for functional training can be quite varied. The utility of elastic type resistance exercise is the versatility of movement as well as the ease of modifying resistance without the exercise having to hold the loads. One challenging aspect of elastic resistance is the difficulty in knowing the loading during the exercise, due to changes as the material is stretched, as well as the changes in material qualities with repeated use [6-11]. This makes exercise prescription and progression in exercise more challenging, due to a lack of understanding loading increments with any precision.

According to the American College of Sports Medicine, proper progression in resistance training occurs when an exerciser makes increases in loading by $2-10 \%$ depending on the size of the muscle group [12] The Core Stix ${ }^{\mathrm{TM}}$ pole system allows a variety of loading schemes, such that as they become stronger, they may increase their loading by simply moving the poles through a greater range of flex. Additional refinement in loading could also be done by either adjusting hand positions on the pole or, if larger loading increases were desired, switching to a different pole. Our data show that variations in tension can range from as little as $0.1 \mathrm{~kg}$ by changing hand position to as much as $10 \mathrm{~kg}$ by changing poles. For clinicians working in rehabilitation settings, the pole tension prevents undue loading of the muscles and joints due to the participant holding the weight. The linearity of tension with degree of flex means that the regression equations provided can give the clinician accurate loading information. With the advent of inclinometers available on smartphone apps, degree of flex measurements become more practical and useful.

For the exerciser self-selecting load, they may self-limit the amount of loading due to an inability for them to flex the pole past a point of injury. Also, as the user fatigues, they would naturally reduce the amount of pole flexion, producing less tension. This would reduce the risk of strain for the user, like how it would likely be for the case of traditional weight lifting. Elastic materials have been found to fatigue and lose their ability to generate the same tension for a given deformation [13]. This can be detrimental in rehabilitation settings and lead for practitioners to increase a patient's resistance when it is not actually appropriate. Although it was not tested in the present study, the fiberglass polymer of the flexible poles is a more robust material than that of elastic bands, which makes use of the poles particularly advantageous. A fiberglass polymer pole training system provides a unique form of elastic resistance, where the poles can be inserted into sockets on the platform in a range of pole positions. This means that a large assortment of exercises can be performed with loads of up to $38 \mathrm{~kg}$ per pole and small increments of loading. Additionally, assisted exercises such as pole-assisted squats mean that the device could be used for rehabilitative purposes for balance impaired or chair bound exercisers.

\section{Conclusion}

The data provides quantified resistances of the Core Stix ${ }^{\mathrm{TM}}$ poles across degrees of pole flexion as well as at various hand grip positions. With this information, practitioners can use these values for reference to prescribe loads that are appropriate for the exerciser. Regarding loading progression, practitioners can also increase loading by either lowering the hand grip position, increasing the amount of pole flexion during the exercise, or switching pole colors to the next progressive level.

\section{Acknowledgement}

The author would like to acknowledge the undergraduate student researchers who assisted with the tension measurements: Robert Albert, Patrick Hoxie, Chandler Babb, and Alex Wong.

\section{References}

1. Hughes CJ, Hurd K, Jones A, Sprigle S (1999) Resistance properties of Thera-band tubing during shoulder abduction exercise. J Orthop Sports Phy Ther 29(7): 413-420.

2. Uchida MC, Nishida MM, Sampaio RAC, Moritani T, Arai H (2016) Theraband ${ }^{\circledR}$ elastic band tension" reference values for physical activity. J Phys Ther Sci 28(4): 1266-1271. 
3. Koch K, Kadar M (2010) Inventors Core Stix Fitness, assignee. Exercise Apparatus. United States patent US 7704199B2.

4. Marino M, Nicholas JA, Gleim GW, Rosenthal P, Nicholas SJ (1982) The efficacy of manual assessment of muscle strength using a new device. Am J Sports Med 10(6): 360-364.

5. Aufsesser P, Horvat M, Croce R (1996) A critical examination of selected hand-held dynamometers to assess isometric muscle strength. Adapted Phy Ed Quart 13(2): 153-165.

6. Martins WR, Carvalho RS, Silva MS, Blasczyk JC, Araújo JA, et al. (2013) Mechanical evaluation of elastic tubes used in physical therapy. Physiotherapy Theory and practice 30(3): 218-222.

7. McMaster DT, Cronin J, McGuigan MR (2010) Quantification of rubber and chain-based resistance modes. J Strength Cond Res 24(8): 20562064.

8. Nyberg A, Hedlund M, Kolberg A, Alm L, Lindstrom B, et al. (2014) The accuracy of using elastic resistance bands to evaluate muscular strength. Eur J Physiotherapy 16(2): 104-112.

\section{ISSN: 2574-1241}

DOI: $10.26717 / B J S T R .2018 .11 .002113$

Steve C Glass. Biomed J Sci \& Tech Res

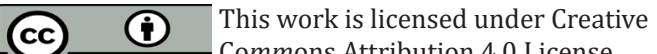
Commons Attribution 4.0 License

Submission Link: https://biomedres.us/submit-manuscript.php
9. Rajkumar R (2015) Load equivalence of transient deformation characteristics of exercise elastic tubes used in physiotherapy rehabilitation and fitness training programs. Int J Physiother Res 3(4): 1156-1162.

10. Thomas M, Muller T, Busse W (2005) Quantification of tension in Theraband and Cando tubing at different strains and starting lengths. J Sports Med Phys Fitness 45: 188-198.

11. Thomas M, Muller T, Busse M (2002) Comparison of tension in Theraband and Cando tubing. J Orthop Sports Phys Ther 32(11): 576-578.

12. American College of Sports Medicine (2009) Progression models in resistance training for healthy adults. Med Sci Sports Ex 41(3): 687-708.

13. Simoneau GG, Bereda SM, Sobush DC, Starsky AJ (2001) Biomechanics of elastic resistance in therapeutic exercise programs. J Orthop Sports Phys Ther 31(1): 16-24

$\begin{array}{ll}\text { BIOMEDICAL } & \text { Assets of Publishing with us } \\ \text { RESEARCHES } & \text { - Global archiving of articles } \\ \text { - Immediate, unrestricted online access }\end{array}$

